\title{
Sean Lucan, MD, MPH, MS Selected as 2016 NAM Puffer/ABFM Fellow
}

\section{Jane Ireland}

The National Academy of Medicine (NAM) has selected Sean Lucan, MD, MPH, MS as the 2016 James C. Puffer, MD/

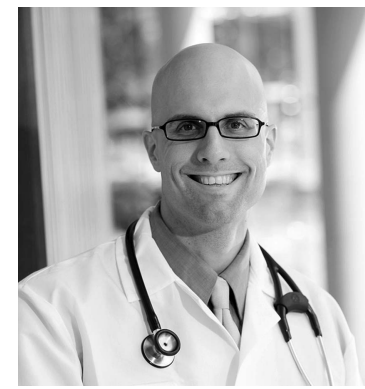

Sean Lucan, MD, MPH, MS American Board of Family Medicine Fellow. Dr. Lucan is a practicing family physician in Bronx, New York, treating children and adults. He is also an award-winning National Institutes of Health-funded investigator who has published numerous peer-reviewed articles and thought pieces on food-related issues. Dr. Lucan has coauthored 1 textbook on nutrition and another on biostatistics, epidemiology, preventive medicine, and public health. He is 1 of 3 outstanding health professionals selected for the class of 2016 NAM Anniversary Fellows.

Dr. Lucan earned his MD and MPH degrees at Yale before completing residency training in Family Medicine and Community Health at the University of Pennsylvania. After residency, he completed a fellowship in the prestigious Robert Wood Johnson Foundation Clinical Scholars Program,

Conflict of interest: The author is the communications editor for the ABFM. where he earned an MS in Health Policy Research. Dr. Lucan is also a former Pisacano Scholar.

Dr. Lucan's research focuses on how different aspects of urban food environments may influence what people eat, and what the implications are for obesity and chronic diseases, particularly in lowincome and minority communities. Another focus of his work is the critical examination of clinical guidance and public health initiatives related to nutrition.

As a Puffer/ABFM/NAM Anniversary Fellow, Dr Lucan will receive a research stipend of $\$ 25,000$. Named in honor of James C. Puffer, MD, president and chief executive officer of the ABFM, the fellowship program enables talented, early career health policy and science scholars in family medicine to participate in the work of the Academies and further their careers as future leaders in the field.

NAM Anniversary Fellows continue their main responsibilities while engaging part-time over a 2-year period in the Academies' health and science policy work. A committee appointed by the president of the Institute of Medicine selects fellows based on their professional accomplishments, potential for leadership in health policy in the field of family medicine, reputation as scholars, and the relevance of their expertise to the work of NAM and the Institute of Medicine.

To see this article online, please go to: bttp://jabfm.org/content/ 30/1/111.full. 